\title{
AN INTELLIGENT MOBILE APPLICATION TO MANAGE College DATABASE AND RECOMMENDATION USING DATA MINING
}

\author{
Yixuan Qi ${ }^{1}$, Qi $\mathrm{Lu}^{2}, \mathrm{Yu} \mathrm{Su}{ }^{3}$ and Fangyan $\mathrm{Zhang}^{4}$ \\ ${ }^{1}$ Valencia High School, Placentia, CA 92870 \\ ${ }^{2}$ Department of Social Science, University of California, Irvine, \\ Irvine, CA, 92697 \\ ${ }^{3}$ Department of Computer Science, California State Polytechnic University, \\ Pomona, CA, 91768 \\ ${ }^{4}$ ASML, San Jose, CA, 95131
}

\begin{abstract}
College application is a critical and complicated task for high school students. Generally speaking, one student will submit an application to a number of universities or colleges. However, there is no proper software for them to organize their application-related information during the application process. This paper proposes an all-in-one system that can contain useful features that help students in their college application, such as compare his or her SAT/GPA, organize their rewards and activities, etc. This tool has been published in Google Play.
\end{abstract}

\section{KEYWORDS}

Android application, App development, Google Drive

\section{INTRODUCTION}

Based on the National Center for Education Statistics, about 19.9 million students are going to colleges in fall 2019. However, as helping tools, there are little resources can be used for college application. College application [1] has always been an endless and tedious process [2] and I have suffered a lot to organize my profile for the past 3 years. There is rarely any professional all-inone application software [3] on the market.

In recent years more and more people are applying to colleges or universities. College application is the thing that most of the students must face and it is a long-term process that takes away people's time and energy. High school students will need to organize all their application-related information during their high school years. Tons of files will need to be distinguished into different categories. Maybe Google Drive [4] and such cloud storage can be used as the folder to store all student's information, a professionally designed software [5] will have a huge impact on the college applicants and high school students who wants to go to college. My project combines the three important features together avoiding additional time-wasting [6] and providing a professional storing folder [7] for a special purpose.

First of all, my project helps high school students who want to go to the college or university, as a data folder storing required personal materials and college information \& requirements for all applicants. Moreover, this project contains the feature that every user can compare his or her 
SAT/GPA/etc. [8]. with those from previous years. I am trying to simplify the college application process by providing a tool that is easy to access and contains an all-in-one system, with college Info \& requirement comparison [9] \& personal organizer [10], for helping college applicants.

There are many websites for people to compare their grades and test scores and such College Board (Figure 1) [11] has its own college information page or google drive can be used as an application folder.

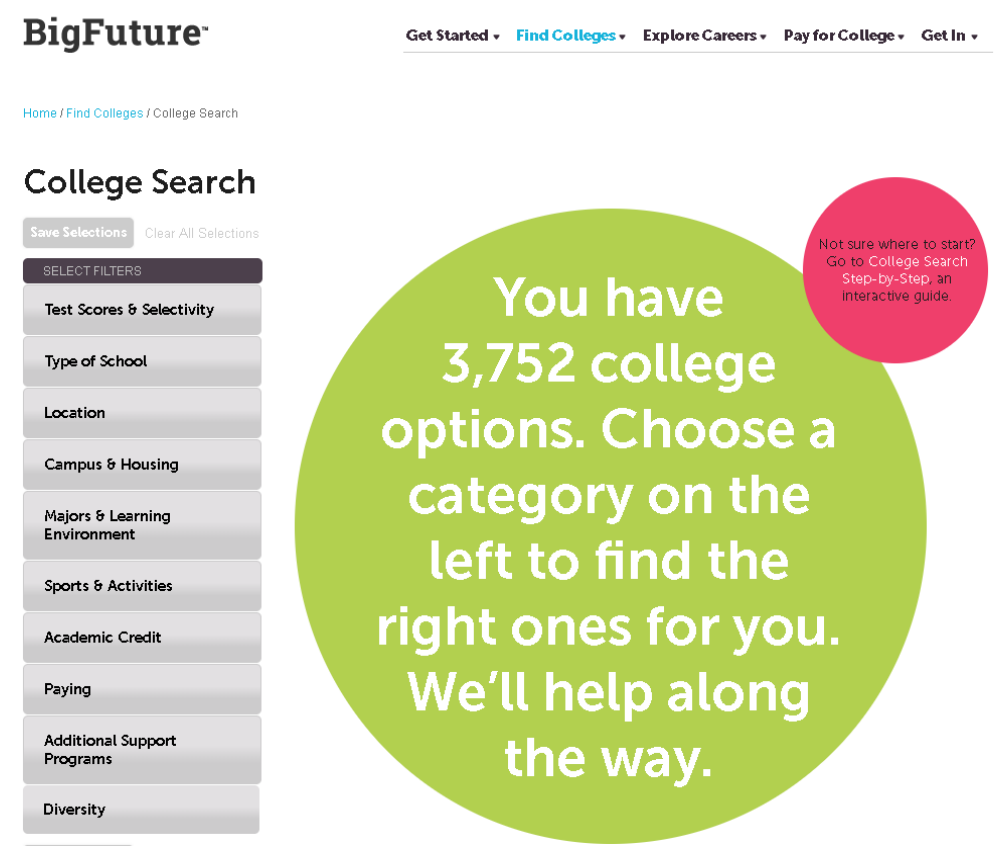

Figure1: CollegeBoardBigFuture

However, these tools/pages are usually not very easy to use or not professional enough.

Sometimes people have to spend hours even days to organize some random files or projects and later they spend even more time finding out the location. There is also some information needed for college application but there is nowhere to keep them.

Websites like USNews (Figure 2) [12] has the most professional information and rankings of most every college and university people are looking for. However, there is usually nowhere to save the information and even there is the progress is very complicated. The information sometimes lacks the accessibility [13] in which makes people's lives much harder. All they need as a college applicant is to manage their time properly but spend hours opening the tabs and pages is really a waste of time.

My method is to create an all-in-one system in which all features are included, and users can use them anytime anywhere. For the information-saver problem, my app has special places for users to input everything needed. For example, they can input all their rewards and activities.

The first 2 sections talk about the significance of college application and the reason that my project is indispensable. Section 3 talks about the features and functions. Section 4 and 5 mainly discuss the benefits and advantages my project has. 


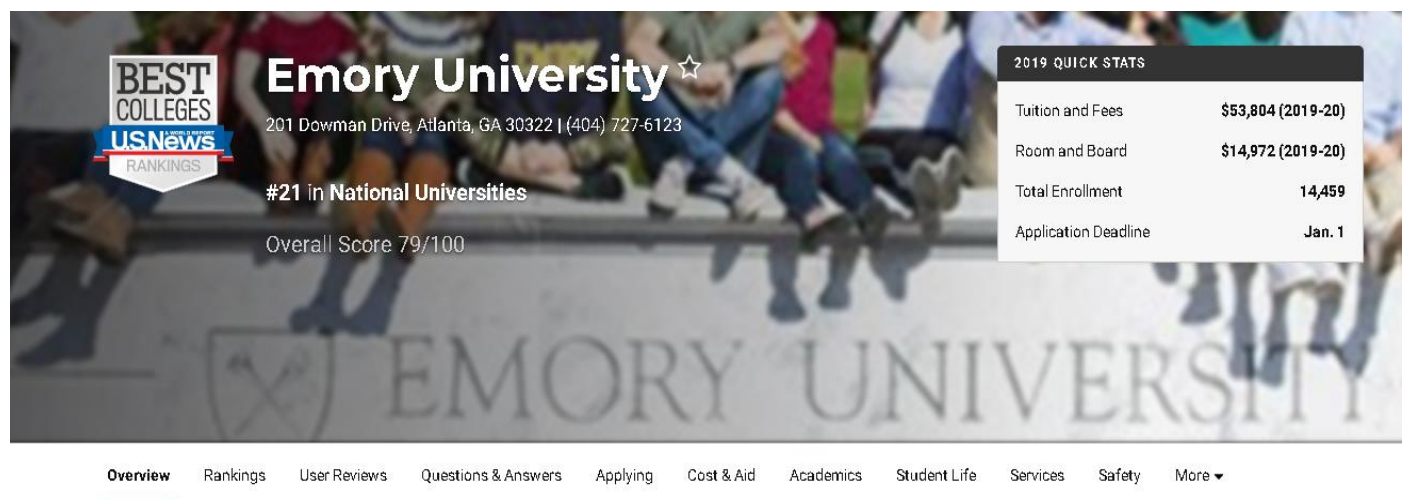

\section{Overview of Emory University}

Emory University is a private institution that was founded in 1836 . It has a total undergraduate enrollment of 7,086, its setting is city, and the campus size is 631 acres. It utilizes a semesterbased academic calendar. Emory University's ranking in the 2020 edition of Best Colleges is National Universities, \#21. Its tuition and fees are $\$ 53,804(2019-20)$.

Emory University, located near downtown Atlanta, is divided into nine schools and colleges, four of which serve undergraduate and graduate students. Emory's graduate programs include the highly ranked Goizueta Business School, School of Law and School of Medicine. First- and second-year students are required to live on campus, but a majority of students remain on campus all four years. The Student Programming Council organizes events and performances throughout the year, including from well-known entertainers and musicians. A popular student organization is

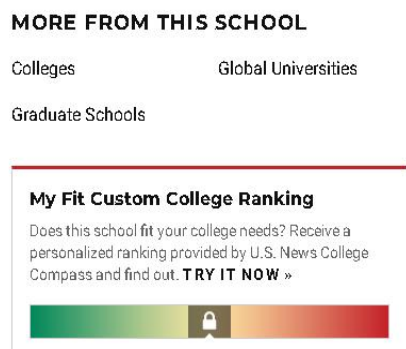

Figure2: USNewsCollegeSearch

\section{Motivation}

I built this app because based on my situation, I think this app could really help those high school students who are going to college or university. I think such an app could save time for them so they can focus on some meaningful tasks instead of wasting time here. The challenge I faced was that I had to decide what function should the app have. The main point of this app is to create efficiency [14], so I had to choose what functions were unnecessary. I interviewed with some students in my high school and made the final decision.

\section{Solution}

First of all, my app starts with a sign up/login page (Figure 3a), where users can create their own accounts the first time, they use it and have their own private online storage [15] parts. After logged in users will go to the main page (Figure 3b) where the four major functions are implemented. Users can go to the specific pages editing their scores, activities, college wish list, and important dates.

If users choose to go to the score page (Figure 5a), they can see all the scores they entered and when then click the add score button they will jump to the other page to add a new score or update the latest scores they have (Figure 5b). After adding/updating the scores, users click the add button and the scores are now added/updated to the cloud storage. New scores are added to the page and undated scores are now storing the latest information (Figure 5c). 


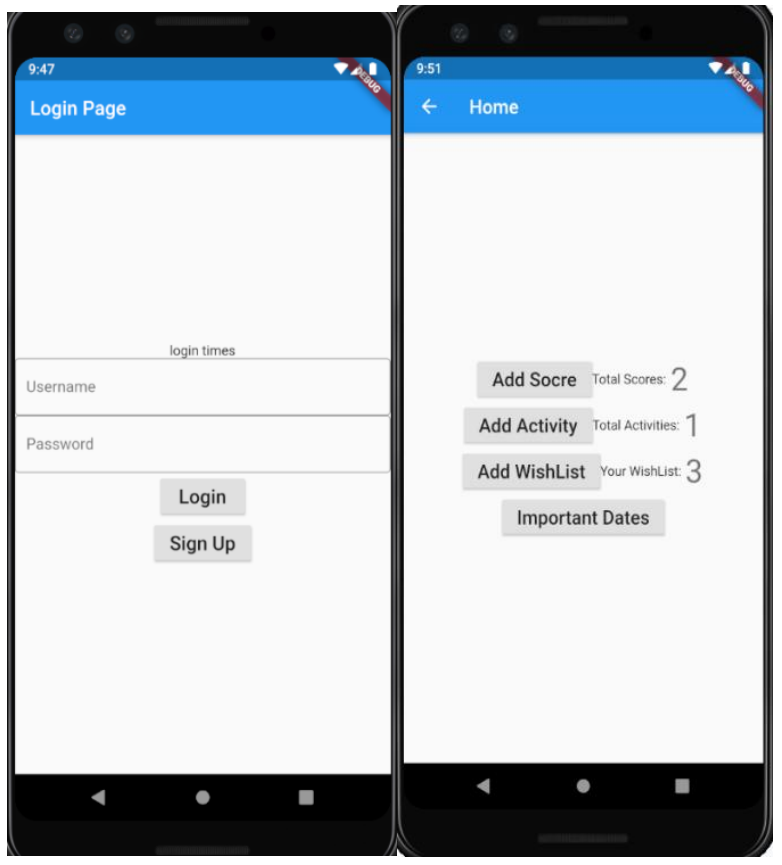

Figure 3: (a) Login Page (b) Main Page

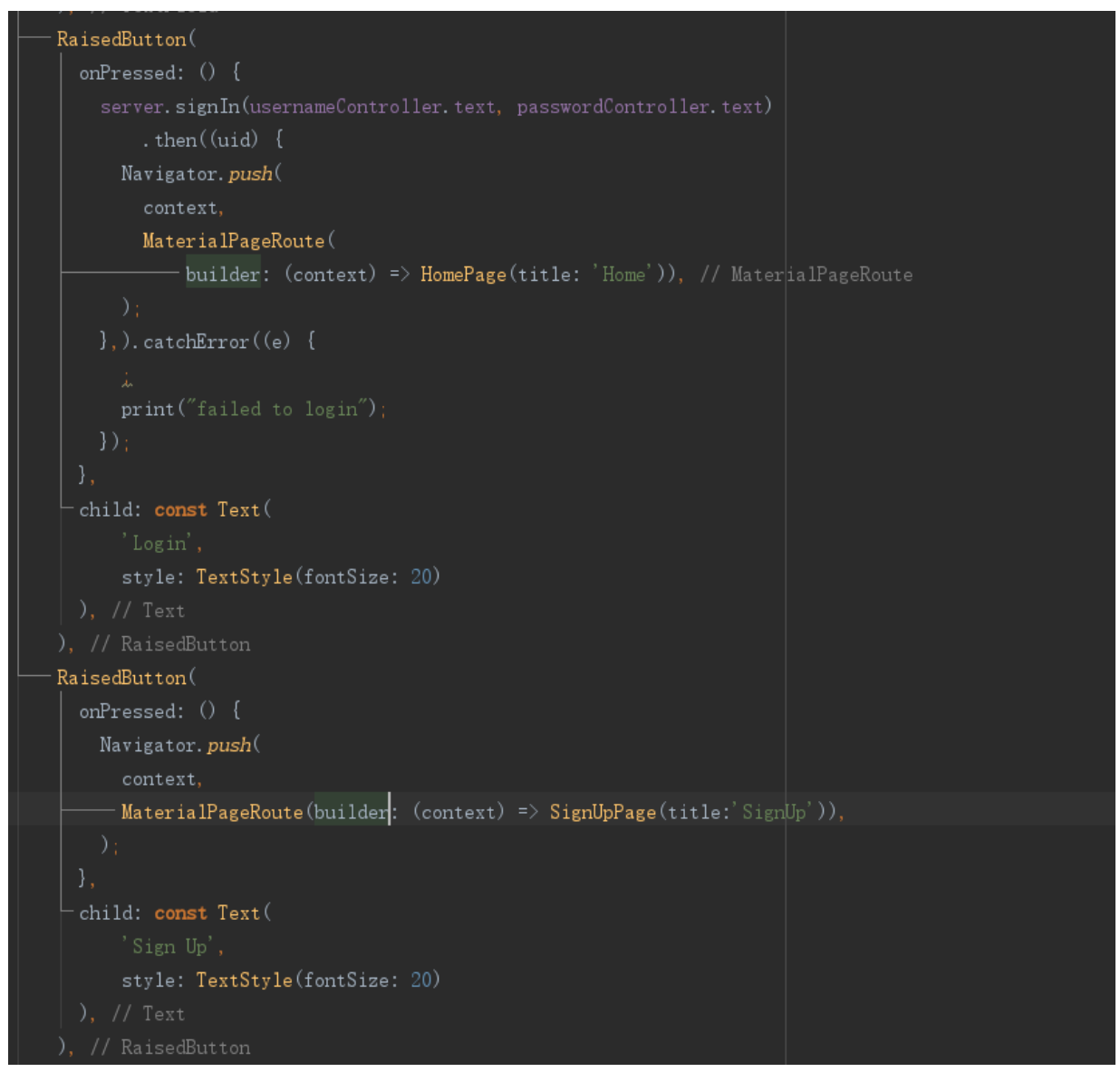

Figure 4: Code for the App 


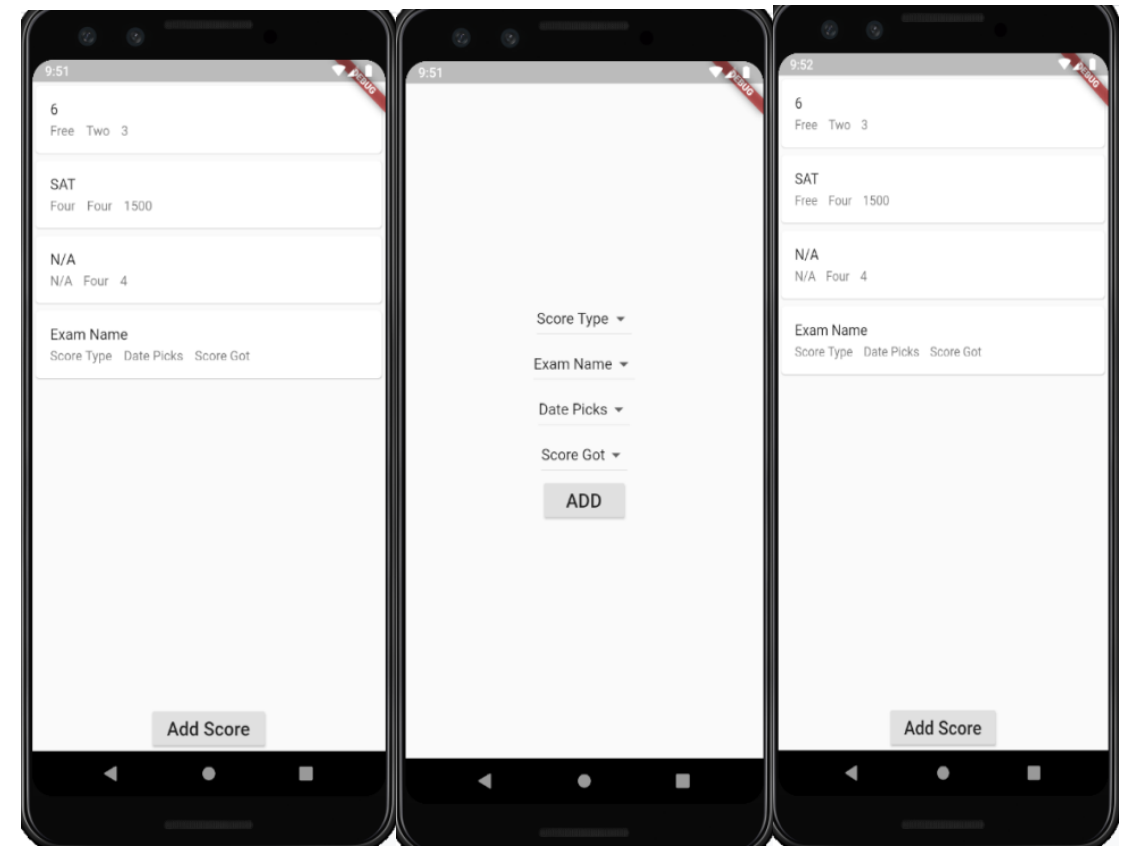

Figure 5: (a) ScoreEntered Page (b) Enter Score Page (c) Back to ScoreEntered Page with New Info

Users could also go to the activity/important Date (Figure 6a and 6c) page by clicking add Activity or add Important Date (Figure 6b) button, the functions are basically the same as the score page where people can edit their activities they have done or important dates they have.

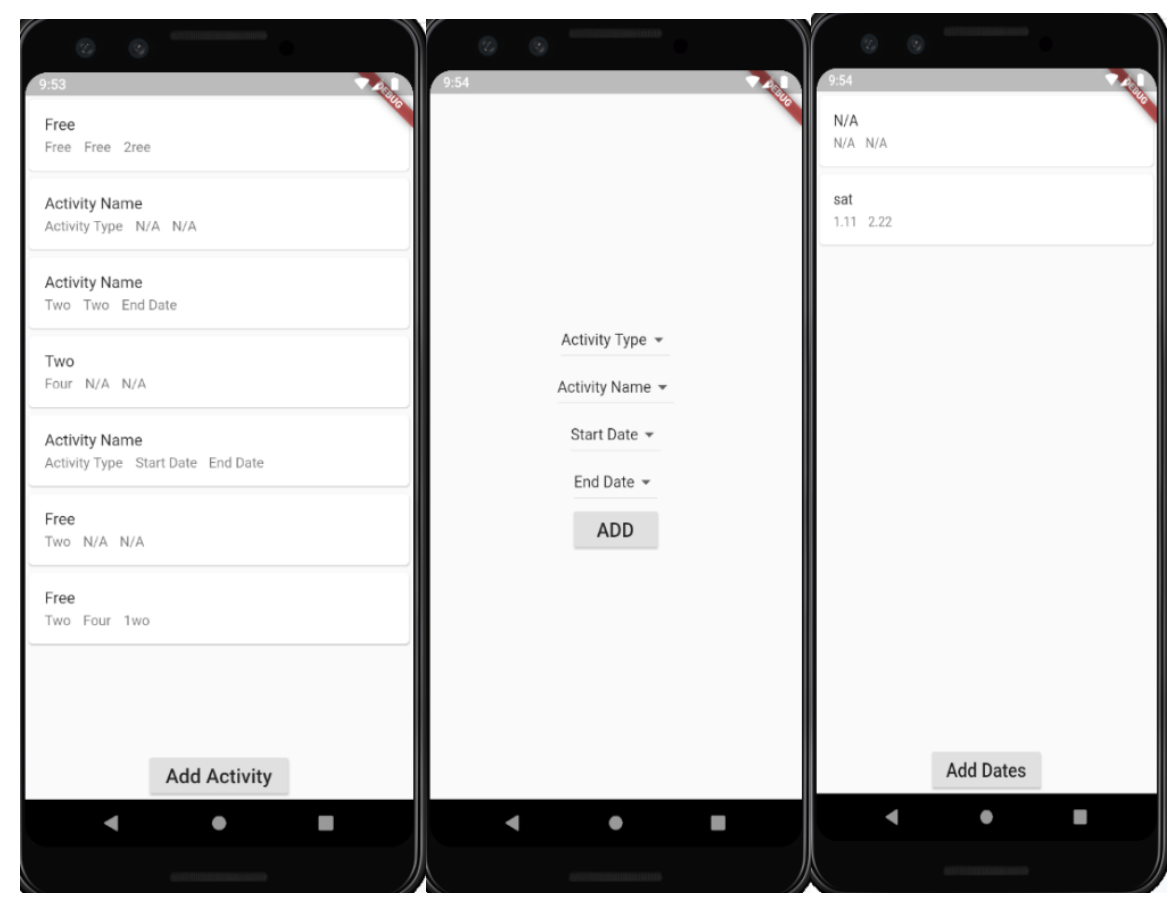

Figure 6: (a) ActivityEntered Page (b)Enter ActivityPage (c) ImportantDate Page

By clicking the Add Wishlist button (7a), users will jump to the college list page and they can find most of the information they need related to the application. 


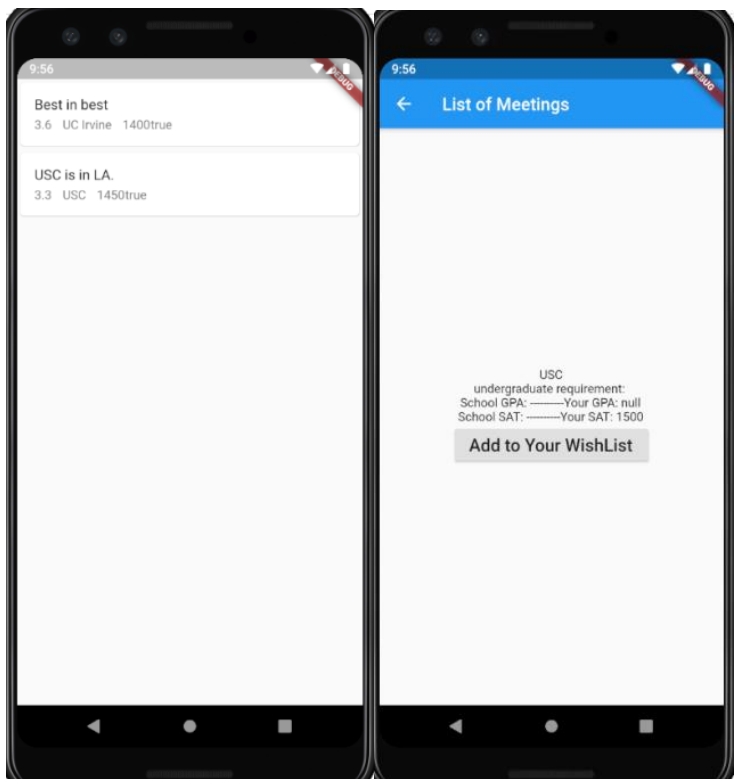

Figure 7: (a) Wishlist Page

(b) Add College Wishlist Page

Users can click the schools they wish to apply, and the app will jump to the Add College Wishlist page (Figure 7b). The page will show basic information about the college/university and there are two comparisons between GPA and sat/act scores. The app will automatically take the scores users entered \& saved to compare to the average applicant's scores. Users can then click AddWishList to add the college to their wish list and the page will jump back to the College Wishlist page. The college/university users selected will be marked with some color/icon presenting the specialty.

\section{RELATED WORK}

Due to the function google drive has, which is an online folder, most college applicants/high school students use Google Drive for storing their related activities, rewards, etc. However, a general folder means that those students have to find the college information elsewhere and after months or even years there is so much information, whether related or not, have to be organized. College Board has its own college wish list where students can select their dream schools and check the information and application requirements. However, students do not have College Board accounts until they are taking their first AP test or SAT test. Moreover, the College Board has little accessibility that barely anyone uses it on the phone or the only thing they do is check their scores.

\section{Conclusion}

In this project, we proposed an all-in-one system that helps high school students in their application. This tool is a mobile app [16] that has been developed to manage application materials. The system is able to alleviate pressure and effectively reduce applicants' duplicate tasks [17]. The result shows that this tool can help high school students in their college application.

As for the future work, we will investigate thoroughly high school student's application process to make sure that the system is updated and cover cases as many as possible. We also would like to explore and make it more complete. 
In addition, one limitation related to the app is that it does not have enough users in test. we plan to add more features to the system in the next version and follow high school students' applications from the beginning to the end.

\section{REFERENCES}

[1] Roderick, Melissa, Vanessa Coca, and Jenny Nagaoka. "Potholes on the road to college: High school effects in shaping urban students' participation in college application, four-year college enrollment, and college match." Sociology of Education 84, no. 3 (2011): 178-211.

[2] Robinson, Karen Jeong, and JosipaRoksa. "Counselors, information, and high school college-going culture: Inequalities in the college application process." Research in Higher Education 57, no. 7 (2016): 845-868.

[3] Hallar, James H., and Wai Lim Chan. "All-in-one information handling system." U.S. Patent Application 29/468,397 filed April 29, 2014.

[4] Quick, Darren, and Kim-Kwang Raymond Choo. "Google Drive: Forensic analysis of data remnants." Journal of Network and Computer Applications 40 (2014): 179-193.

[5] Quinn, James Brian, Philip Anderson, and Sydney Finkelstein. "Managing professional intellect: making the most of the best." The strategic Management of Intellectual capital 87100 (1998).

[6] Haycock, Kati, and Stephanie Robinson. "Time-Wasting Workshops?" Journal of Staff Development 22, no. 2 (2001): 16-18.

[7] Behrens, Dietmar, Waldemar Hoog, and Rudolf Zimmermann. "Device for storing a data diskette in a file folder." U.S. Patent 4,884,691 issued December 5, 1989.

[8] Noftle, Erik E., and Richard W. Robins. "Personality predictors of academic outcomes: big five correlates of GPA and SAT scores." Journal of personality and social psychology 93, no. 1 (2007): 116 .

[9] Echerer, Scott J., and Stephen R. McNeill. "Radiographic image enhancement comparison and storage requirement reduction system." U.S. Patent 5,740,267 issued April 14, 1998.

[10] Randall, Stephen. "Electronic personal organizer." U.S. Patent 5,237,651 issued August 17, 1993.

[11] Ramist, Leonard. "College Student Attrition and Retention. College Board Report No. 81-1." (1981).

[12] Weaver, David Hugh, G. Cleveland Wilhoit, and Lori A. Bergen. The American journalist: A portrait of US news people and their work. Indiana University Press, 1991.

[13] Clemons, Eric K., and Steven O. Kimbrough. "Information systems, telecommunications, and their effects on industrial organization." (1986).

[14] Ross, Stephen A. "Options and efficiency." The Quarterly Journal of Economics 90, no. 1 (1976): 75-89.

[15] Gonzalez, José Luis, Jesus Carretero Perez, Victor Sosa-Sosa, Juan F. Rodriguez Cardoso, and Ricardo Marcelin-Jimenez. "An approach for constructing private storage services as a unified faulttolerant system." Journal of Systems and Software 86, no. 7 (2013): 1907-1922.

[16] Joorabchi, Mona Erfani, Ali Mesbah, and Philippe Kruchten. "Real challenges in mobile app development." In 2013 ACM/IEEE International Symposium on Empirical Software Engineering and Measurement, pp. 15-24. IEEE, 2013.

[17] Da-You, LI Jia-Fei LIU, and Y. A. N. G. Bo. "Process Mining: An Extended $\alpha$-Algorithm to Discovery Duplicate Tasks [J]." Chinese Journal of Computers 8 (2007). 